\title{
Plasma Procalcitonin: Another Arrow in Our Quiver?
}

One of the key issues in the management of intensive care unit (ICU) patients suspected of having developed nosocomial pneumonia is to distinguish patients with true pneumonia from those with only proximal airways colonization. ${ }^{1,2}$ Prompt and specific identification of patients with true pulmonary bacterial infection might enable antibiotics to be initiated rapidly while avoiding their overuse. Concern about the inaccuracy of conventional approaches to hospital-acquired pneumonia (HAP) and ventilator-associated pneumonia (VAP) recognition and the impossibility of using such strategies to avoid over-prescription of antibiotics has led some investigators to postulate that use of biological markers, such as procalcitonin, might improve identification of patients with true VAP and facilitate the decision about whether to treat.

\section{See the Original Study on Page 412}

Procalcitonin is a 116-amino-acid peptide devoid of known hormonal activity, and is one of the precursors of the hormone calcitonin. After translation from calcitonin mRNA, procalcitonin is cleaved into 3 distinct molecules: calcitonin, katacalcin, and an $\mathrm{N}$-terminal fragment. Procalcitonin is normally produced in the $\mathrm{C}$ cells of the thyroid and immediately cleaved, with only a very small fraction being released into the bloodstream. Blood procalcitonin levels in healthy individuals are therefore very low $(<0.1 \mathrm{ng} / \mathrm{mL}){ }^{3,4}$ However, via microbial toxins and certain bacterium-specific pro-inflammatory cytokines, such as interleukin-1b, tumor necrosis factor- $\alpha$, and interleukin-6, microbial infections induce a ubiquitous increase of calcitonin gene expression and a constitutive release of procalcitonin from all parenchymal tissues and differentiated cell types throughout the body. ${ }^{3,4}$ Under these conditions, the procalcitonin level may rise to $>100 \mathrm{ng} / \mathrm{mL}$, without any increase of calcitonin level, because enzymatic cleavage of calcitonin is bypassed. Its precise role during sepsis is not fully understood, but it has been shown, in animal models of sepsis, that procalcitonin administration increased mortality and that antibody neutralization of procalcitonin improved survival. ${ }^{5-7}$

Numerous studies have evaluated the accuracy of determination of procalcitonin compared to C-reactive protein for the diagnosis of bacterial infection. In a metaanalysis that included published studies that evaluated these markers for the diagnosis of bacterial infections in hospitalized patients, procalcitonin level was more sensitive (88\% [95\% CI $80-93 \%$ ] vs $75 \%$ [95\% CI 62-84\%]) and more specific $(81 \%$ [95\% CI 67-90\%] vs 67\% [95\% CI 56$77 \%]$ ) than C-reactive protein level for differentiating bacterial from noninfectious causes of inflammation. ${ }^{8}$ These findings were confirmed and extended in a more recent meta-analysis, based on 25 studies that evaluated the diagnostic accuracy of this marker in the ICU. ${ }^{9}$ However, procalcitonin has also been reported to be increased in different non-septic conditions, such as major trauma, surgery, acute respiratory distress syndrome, rejection after transplantation, cardiogenic shock, severe burns, and heatstroke. ${ }^{10}$ In such cases, circulating levels of several calcitonin precursors, including procalcitonin, can also increase up to several hundred-fold. Follow-up and re-evaluation of procalcitonin in clinical suspicion of infection is therefore pivotal to any management strategy based on such a marker.

A paper by Dallas et al in this issue of ResPiRATORY CARE presents important information about the potential usefulness of this marker for diagnosing nosocomial pneumonia in the ICU and provides simultaneously sobering and encouraging insights into strategies to improve the conduct of antimicrobial therapy in patients with HAP/ VAP. ${ }^{11}$ In this very well done study, which enrolled a large number of consecutive ICU patients with a clinical suspicion of HAP/VAP, Dallas et al clearly demonstrate that the measurement of plasma procalcitonin has minimal diagnostic value. Although the mean procalcitonin concentration was somewhat greater in patients with definite nosocomial pneumonia than in those with definite absence of pneumonia $(18.3 \pm 99.1 \mathrm{ng} / \mathrm{mL}$ vs $1.7 \pm 2.0 \mathrm{ng} / \mathrm{mL}$, respectively, difference not significant), the receiver operating characteristic curve and multivariate logistic regression analyses showed that measurement of procalcitonin was inferior to clinical variables for diagnosing nosocomial pneumonia. Using a cutoff value for the procalcitonin concentration of $1 \mathrm{ng} / \mathrm{mL}$, at the time pneumonia was clinically suspected, yielded a diagnostic sensitivity of 50\%, specificity of $49 \%$, positive predictive value of $64 \%$, and negative predictive value of $35 \%$ for definite pneumonia.

These results are well in accordance with several other investigations that also failed to show any real clinical utility of procalcitonin blood level for diagnosing HAP/ VAP. ${ }^{12-15}$ In the only study in which procalcitonin was found to be a good diagnostic marker for VAP, only 20 


\section{Plasma Procalcitonin: Another Arrow in Our Quiver?}

patients were included and those with a previous infection during the same hospitalization were excluded, limiting the potential value of this marker to a very limited subset of ICU patients. ${ }^{16}$ Several factors could explain these results. First, pneumonia may be a localized infection, within which procalcitonin can be synthesized locally without systemic release (as in other such compartmentalized infections), thereby explaining its low serum level or apparent decline in patients with true pulmonary infections. Second, during the same hospitalization, ICU patients may suffer from previous severe sepsis or septic shock, multiorgan failure, or may have developed a systemic inflammation response syndrome after surgery or trauma, conditions known to increase circulating levels of biomarkers, including procalcitonin, in the absence of infection, as indicated above. Thus, a high procalcitonin concentration the day VAP is suspected is not useful, because it is not possible to distinguish an elevation attributable to a prior non-infectious condition from one due to an active infection. Third, it is known that a time lag of $24-48$ hours can exist between bacterial infection onset and peak procalcitonin release, and that might also explain the apparently low procalcitonin level the day of VAP onset. ${ }^{17}$

Although the value of procalcitonin for establishing the diagnosis of HAP/VAP is poor, some results of the study by Dallas et $\mathrm{al}^{11}$ pinpoint the potential interest of this molecule for improving the conduct of antimicrobial therapy in the ICU. Compared to patients with an initial procalcitonin value $>1 \mathrm{ng} / \mathrm{mL}$, those with lower procalcitonin values had fewer total antibiotic days $(13.0 \pm 10.3 \mathrm{~d}$ vs $19.7 \pm 12.0 \mathrm{~d}, P<.001)$ and a lower hospital mortality ( $31 \%$ vs $16 \%, P=.07$ ). Furthermore, when the procalcitonin declined to a low level after 48 hours of treatment, the prognosis was improved and the mortality was significantly decreased, compared to patients with a persistently high $(>1 \mathrm{ng} / \mathrm{mL})$ concentration ( $37 \%$ vs $10 \%, P=.002)$. This is well in accordance with other investigations that documented the prognosis value of elevated procalcitonin concentration at baseline and of its kinetic during the first days of treatment. ${ }^{13,14}$ For example, in a series of 63 consecutive patients with microbiologically proven VAP, a rapid decrease in procalcitonin serum level was associated with good outcome, whereas an increase or no decrease was associated with poor outcome. ${ }^{13}$ Thus, serum procalcitonin level may provide an opportunity to change the treatment strategy early in the course of patients who develop VAP: either to intensify treatment when the procalcitonin level stays "high" or to avoid unnecessary prolonged antibiotics when procalcitonin level rapidly decreases.

Two randomized controlled studies have already been performed to evaluate the potential utility of a procalcitonin-guided strategy to reduce antibiotic duration in patients with VAP. ${ }^{18,19}$ Stolz et al randomized 101 patients with VAP to be managed with an antibiotic discontinuation strategy according to guidelines (control group) or to serum procalcitonin concentration. In patients randomized in the procalcitonin group, attending physicians were recommended to stop antibiotics when the procalcitonin concentration was below $0.5 \mathrm{ng} / \mathrm{mL}$ or had decreased by more than $80 \%$ from the baseline value. Using this algorithm, the number of antibiotic-free days alive within 28 days after VAP diagnosis was significantly higher in the procalcitonin group than in the control group (median $13 \mathrm{~d}$ [IQR 2-21 d] vs $9.5 \mathrm{~d}$ [IQR $1.5-17 \mathrm{~d}]$ ). This reduction in antibiotic administration was not associated with a worse outcome, since ventilator-free days, ICU-free days, hospital stay, 28-day mortality, and hospital mortality rate were similar in the 2 groups. ${ }^{18}$ Similar results were observed by Bouadma et al in the Use of Procalcitonin to Reduce Patients' Exposure to Antibiotics in Intensive Care Units (PRORATA) trial, a randomized trial that included 621 ICU patients, of whom 141 had microbiologically proven VAP. Using predefined algorithms to initiate or discontinue antibiotics according to serum procalcitonin level, the duration of antibiotic treatment for the first episode was also significantly decreased in the 75 patients randomized in the procalcitonin-guided group, compared to the control group managed using international and local guidelines $(7.3 \pm 5.3 \mathrm{~d}$ vs $9.4 \pm 5.7 \mathrm{~d}$, respectively, $P=.02)$, with no detrimental effects on patient outcomes. ${ }^{19}$

Although additional studies will be needed to confirm whether procalcitonin guidance can help reduce antibiotic use in ICU patients with HAP/VAP, the paper by Dallas et al $^{11}$ should provide encouragement to continue to evaluate such a strategy and convince ICU doctors that it is possible to reduce antibiotic use in the ICU.

\section{Charles-Edouard Luyt MD PhD Jean Chastre MD \\ Service de Réanimation Médicale Institut de Cardiologie Groupe Hospitalier Pitié-Salpêtrière Assistance Publique-Hôpitaux de Paris Paris, France}

\section{REFERENCES}

1. Chastre J, Fagon JY. Ventilator-associated pneumonia. Am J Respir Crit Care Med 2002;165(7):867-903.

2. American Thoracic Society; Infectious Diseases Society of America. Guidelines for the management of adults with hospital-acquired, ventilator-associated, and healthcare-associated pneumonia. Am J Respir Crit Care Med 2005;171(4):388-416.

3. Müller B, Becker KL. Procalcitonin: how a hormone became a marker and mediator of sepsis. Swiss Med Wkly 2001;131(41-42):595-602.

4. Müller B, White JC, Nylén ES, Snider RH Jr, Becker KL, Habener JF. Ubiquitous expression of the calcitonin-i gene in multiple tissues in response to sepsis. J Clin Endocrinol Metab 2001;86(1):396-404. 


\section{Plasma Procalcitonin: Another Arrow in Our Quiver?}

5. Nylén ES, Whang KT, Snider RH Jr, Steinwald PM, White JC, Becker KL. Mortality is increased by procalcitonin and decreased by an antiserum reactive to procalcitonin in experimental sepsis. Crit Care Med 1998;26(6):1001-1006.

6. Wagner KE, Martinez JM, Vath SD, Snider RH, Nylén ES, Becker $\mathrm{KL}$, et al. Early immunoneutralization of calcitonin precursors attenuates the adverse physiologic response to sepsis in pigs. Crit Care Med 2002;30(10):2313-2321.

7. Becker KL, Nylén ES, Snider RH Jr, Müller B, White JC. Immunoneutralization of procalcitonin as therapy of sepsis. J Endotoxin Res 2003;9(6):367-374.

8. Simon L, Gauvin F, Amre DK, Saint-Louis P, Lacroix J. Serum procalcitonin and $\mathrm{C}$-reactive protein levels as markers of bacterial infection: a systematic review and meta-analysis. Clin Infect Dis 2004;39(2):206-217. Erratum in: Clin Infect Dis 2005;40(9):13861388.

9. Uzzan B, Cohen R, Nicolas P, Cucherat M, Perret GY. Procalcitonin as a diagnostic test for sepsis in critically ill adults and after surgery or trauma: a systematic review and meta-analysis. Crit Care Med 2006;34:1996-2003.

10. Chastre J, Luyt CE, Trouillet JL, Combes A. New diagnostic and prognostic markers of ventilator-associated pneumonia. Curr Opin Crit Care 2006;12(5):446-451.

Dr Luyt has disclosed relationships with Brahms, bioMérieux, and MSD Pharma. Dr Chastre has disclosed relationships with Sanofi-Aventis, Brahms, Nektar-Bayer, Pfizer, Janssen-Cilag, and Astellas.

Correspondence: Jean Chastre MD, Service de Réanimation Médicale, Institut de Cardiologie, Groupe Hospitalier Pitié-Salpêtrière, 47-83 Boulevard de l'Hôpital, 75651 Paris Cedex 13, France. E-mail: jean.chastre@ psl.aphp.fr.

DOI: $10.4187 /$ respcare.01285
11. Dallas J, Brown SM, Hock K, Scott MG, Skrupky LP, Boyle WA, Kollef MH. Diagnostic utility of plasma procalcitonin for nosocomial pneumonia in the intensive care unit setting. Respir Care 2011; 56(4):412-419.

12. Duflo F, Debon R, Monneret G, Bienvenu J, Chassard D, Allaouchiche B. Alveolar and serum procalcitonin: diagnostic and prognostic value in ventilator-associated pneumonia. Anesthesiology 2002;96(1):7479.

13. Luyt CE, Guerin V, Combes A, Trouillet JL, Ayed SB, Bernard M, et al. Procalcitonin kinetics as a prognostic marker of ventilatorassociated pneumonia. Am J Respir Crit Care Med 2005;171(1):4853.

14. Seligman R, Meisner M, Lisboa TC, Hertz FT, Filippin TB, Fachel $\mathrm{JM}$, et al. Decreases in procalcitonin and C-reactive protein are strong predictors of survival in ventilator-associated pneumonia. Crit Care 2006;10(5):R125.

15. Jung B, Embriaco N, Roux F, Forel JM, Demory D, Allardet-Servent $\mathrm{J}$, et al. Microbiogical data, but not procalcitonin improve the accuracy of the clinical pulmonary infection score. Intensive Care Med 2010;36(5):790-798.

16. Ramirez P, Garcia MA, Ferrer M, Aznar J, Valencia M, Sahuquillo $\mathrm{JM}$, et al. Sequential measurements of procalcitonin levels in diagnosing ventilator-associated pneumonia. Eur Respir J 2008;31(2): 356-362.

17. Luyt CE, Combes A, Reynaud C, Hekimian G, Nieszkowska A, Tonnellier M, et al. Usefulness of procalcitonin for the diagnosis of ventilator-associated pneumonia. Intensive Care Med 2008;34(8): 1434-1440.

18. Stolz D, Smyrnios N, Eggimann P, Pargger H, Thakkar N, Siegemund $\mathrm{M}$, et al. Procalcitonin for reduced antibiotic exposure in ventilator-associated pneumonia: a randomised study. Eur Respir J 2009;34(6): 1364-1375.

19. Bouadma L, Luyt CE, Tubach F, Cracco C, Alvarez A, Schwebel C, et al. Use of procalcitonin to reduce patients' exposure to antibiotics in intensive care units (PRORATA trial): a multicentre randomised controlled trial. Lancet 2010;375(9713):463-474. 